\title{
El poblado naviforme de Cap de Barbaria II (Formentera, Islas Baleares). Nuevos datos sobre su cronología y secuencia de ocupación*
}

\author{
The Naviform village of Cap de Barbaria II (Formentera, Balearic Islands). \\ New data about its chronology and occupation sequence.
}

\author{
Pau Sureda ${ }^{a}$, Edgard Camarós $^{\mathrm{b}}$, Marián Cueto $^{\mathrm{c}}$, Luis C. Teira ${ }^{\mathrm{d}}$, Esteban Álvarez-Fernández \\ e Inés López-Dóriga ${ }^{f}$
}

\section{RESUMEN}

En este trabajo presentamos un conjunto de $6 \mathrm{fe}$ chas de carbono 14 del poblado de Cap de Barbaria II (Formentera, Islas Baleares), que permiten acotar su ocupación dentro de la Edad del Bronce. Además, se tratan aspectos metodológicos relativos a la calibración e interpretación de las fechas en función de la naturaleza de las muestras (hueso y concha). La información delimita cronológicamente el grupo arqueológico naviforme en las islas Pitiusas (Ibiza y Formentera) y proporciona datos importantes para la comprensión de su formación, desarrollo y extinción en el conjunto del archipiélago balear.

\begin{abstract}
We present a series of six radiocarbon dates from the site of Cap de Barbaria II (Formentera, Balearic Islands). These place its occupation in the Bronze Age. In addition, methodological aspects of date calibration according to the nature of the samples (animal bone and shell) are discussed. This information defines chronological time span of the Naviform societies in the islands of Ibiza and Formentera and provides important elements for the understanding the formation, development, and end of these societies throughout the Balearic archipelago.
\end{abstract}

Palabras clave: Islas Baleares; Formentera; Naviforme; Radiocarbono; Edad del Bronce; Mediterráneo occidental.

Key words: Balearic Islands; Formentera; Naviform; Radiocarbon; Bronze Age; Western Mediterranean.

\footnotetext{
* Este artículo se ha desarrollado bajo los objetivos científicos y financiación de los proyectos: HAR2012-36602; HAR201232620; HAR2011-29907-C03-03/HIST dentro de los programas I+D del MINECO y el MICIN. La investigación de PS y EC ha contado con financiación del FI-DGR (AGAUR- Generalitat de Catalunya) y las excavaciones en Cap de Barbaria II del Consell Insular de Formentera.

a Instituto de Ciencias del Patrimonio (Incipit) - Consejo Superior de Investigaciones Científicas (CSIC). Avenida de Vigo s/n. 15705 Santiago de Compotela. España. Correo e.: pau.sureda.torres@gmail.com http://orcid.org/0000-0003-4366-6489

b Institut Català de Paleoecologia Humana i Evolució Social (IPHES) - Universitat Rovira i Virgili (URV). C/Marcel.lí Domingo s/n. Campus Sescelades URV (Edifici W). 43007 Tarragona. España. Correo e.: edgard.camaros@gmail.com http://orcid.org/00000002-0119-3807.

c Dept. de Prehistoria, Universitat Autònoma de Barcelona, Facultat de Filosofia i Lletres. 08193 Bellaterra. España. Correo e.: mariancuetor@gmail.com http://orcid.org/0000-0001-7989-9925.

d Instituto Internacional de Investigaciones Prehistóricas de Cantabria (IIIPC-UC), Edif. Interfacultativo. Avda. de los Castros 51. 39005 Santander. España. Correo e.: luis.teira@unican.es http://orcid.org/0000-0002-3213-0008.

e Dpto. de Prehistoria, Historia Antigua y Arqueología, Universidad de Salamanca. C/ Cerrada de Serranos s/n. 37002 Salamanca. España. Correo e.: epanik@usal.es http://orcid.org/0000-0002-7895-3421.

${ }^{f}$ Wessex Archaeology, Portway House. Old Sarum Park. Salisbury. Wiltshire SP4 6EB. Reino Unido. Correo e.: i.lopezdoriga@wessexarch.co.uk http://orcid.org/0000-0002-2527-3828.

Recibido 16-I-2017; aceptado 16-IV-2017.
}

Copyright: (C) 2017 CSIC. Este es un artículo de acceso abierto distribuido bajo los términos de una licencia de uso y distribución Creative Commons Attribution (CC-by) España 3.0. 


\section{INTRODUCCIÓN}

La Prehistoria de las islas Pitiusas (Ibiza y Formentera) ha sido y es uno de los períodos que más dudas plantea de la investigación arqueológica en las Islas Baleares. La falta de contextos arqueológicos excavados en extensión, la publicación parcial de los resultados y la precariedad del registro arqueológico son algunos de los aspectos
R. Micó (2005) recoge y sintetiza de forma crítica toda la información radiométrica disponible para el archipiélago balear, construyendo la base sobre la que se estructuran las diferentes propuestas de periodización hoy vigentes. De ellas se infiere que el conjunto de las islas Baleares fue colonizado a finales del III milenio cal ANE (Alcover 2008; Lull et al. 2008; Ramis 2014) y que a estos primeros pobladores (relacionados con

\begin{tabular}{|c|c|c|c|c|c|c|c|c|}
\hline Yacimiento & Laboratorio & C14 (BP) & $\begin{array}{c}\text { Cal } 1 \sigma \\
(68,2 \% \text { c. })\end{array}$ & $\begin{array}{c}\text { Cal } 2 \sigma \\
(95,4 \% \text { c. })\end{array}$ & Muestra & Contexto & Referencia & Comentario \\
\hline Ca na Costa & KIA-14329 & $3595 \pm 35$ & $\begin{array}{c}\text { 2013-1902 } \\
\text { cal ANE }\end{array}$ & $\begin{array}{c}\text { 2113-1830 } \\
\text { cal ANE }\end{array}$ & Humana & $\begin{array}{l}\text { Huesos } \\
\text { de la cámara }\end{array}$ & Costa y Benito 2000 & Nivel de uso \\
\hline Ca na Costa & KIA-14330 & $3535 \pm 40$ & $\begin{array}{l}\text { 1932-1776 } \\
\text { cal ANE }\end{array}$ & $\begin{array}{c}\text { 1973-1748 } \\
\text { cal ANE }\end{array}$ & Humana & $\begin{array}{c}\text { Huesos } \\
\text { de la cámara }\end{array}$ & Costa y Benito 2000 & Nivel de uso \\
\hline Ca na Costa & BM-1677 & $3270 \pm 80$ & $\begin{array}{c}\text { 1630-1452 } \\
\text { cal ANE }\end{array}$ & $\begin{array}{c}\text { 1743-1406 } \\
\text { cal ANE }\end{array}$ & Humana & $\begin{array}{c}\text { Huesos } \\
\text { de la cámara }\end{array}$ & Micó 2005: 61-62 & $\begin{array}{l}\text { Problemas. } \\
\text { Descartar }\end{array}$ \\
\hline Can Sergent & BM-1510 & $2500 \pm 100$ & & $\begin{array}{l}\text { 814-399 } \\
\text { cal ANE }\end{array}$ & Humana & $\begin{array}{c}\text { Huesos } \\
\text { de la cámara }\end{array}$ & $\begin{array}{l}\text { Fernández et al. 1984: } \\
767\end{array}$ & $\begin{array}{l}\text { Muy imprecisa. } \\
\text { Descartar }\end{array}$ \\
\hline Can Sergent & BM-1511 & $2670 \pm 60$ & $\begin{array}{l}895-799 \\
\text { cal ANE }\end{array}$ & $\begin{array}{l}976-768 \\
\text { cal ANE }\end{array}$ & Humana & $\begin{array}{l}\text { Huesos } \\
\text { de la cámara }\end{array}$ & $\begin{array}{c}\text { Fernández et al. 1984: } \\
767 \\
\end{array}$ & Nivel de uso \\
\hline Cap de Barbaria II & UtC-8320 & $2393 \pm 43$ & $\begin{array}{l}\text { 536-401 } \\
\text { cal ANE }\end{array}$ & $\begin{array}{l}\text { 749-390 } \\
\text { cal ANE }\end{array}$ & Fauna & $\begin{array}{l}\text { Àmbit 5-A, } \\
\text { Nivell } 2 \mathrm{~b}\end{array}$ & Micó 2005: 84 & $\begin{array}{l}\text { Muy moderna. } \\
\text { Descartar }\end{array}$ \\
\hline Cova des Riuets & $\begin{array}{l}\text { BETA- } \\
171380 \\
\end{array}$ & $3580 \pm 40$ & $\begin{array}{c}\text { 2011-1886 } \\
\text { cal ANE }\end{array}$ & $\begin{array}{c}2035-1776 \\
\text { cal ANE }\end{array}$ & Fauna & UE-12 & López Garí et al. 2013 & Nivel de uso \\
\hline Cova des Riuets & $\begin{array}{l}\text { BETA- } \\
171381 \\
\end{array}$ & $3550 \pm 40$ & $\begin{array}{l}\text { 1949-1780 } \\
\text { cal ANE }\end{array}$ & $\begin{array}{c}\text { 2016-1756 } \\
\text { cal ANE }\end{array}$ & Carbón & UE-12 & López Garí et al. 2013 & $\begin{array}{l}\text { Nivel de uso. } \\
\text { Impreciso }\end{array}$ \\
\hline Es Pouàs & KIA-29163 & $3785 \pm 25$ & $\begin{array}{l}\text { 2279-2146 } \\
\text { cal ANE }\end{array}$ & $\begin{array}{c}2289-2140 \\
\text { cal ANE }\end{array}$ & Humana & Descnocido & Alcover 2008 & Nivel de uso \\
\hline $\begin{array}{l}\text { Puig de Ses } \\
\text { Torretes }\end{array}$ & UtC-8319 & $3645 \pm 42$ & $\begin{array}{c}\text { 2121-1948 } \\
\text { cal ANE }\end{array}$ & $\begin{array}{c}\text { 2138-1908 } \\
\text { cal ANE }\end{array}$ & Fauna & $\begin{array}{l}\text { Estructura 01, } \\
\text { Nivel } 3 .\end{array}$ & Costa y Benito 2000 & Nivel de uso \\
\hline Puig des Molins & UtC-11185 & $2531 \pm 42$ & $\begin{array}{l}\text { 793-556 } \\
\text { cal ANE }\end{array}$ & $\begin{array}{l}801-537 \\
\text { cal ANE }\end{array}$ & Humana & $\begin{array}{l}\text { Incineración } 1 \\
\text { (Sector NO) }\end{array}$ & Fernández y Costa 2004 & Muy imprecisa \\
\hline Puig des Molins & UtC-11186 & $2711 \pm 38$ & $\begin{array}{l}\text { 896-824 } \\
\text { cal ANE }\end{array}$ & $\begin{array}{l}\text { 926-803 } \\
\text { cal ANE }\end{array}$ & Humana & $\begin{array}{c}\text { Incineración } 2 \\
\text { (Sector NO) }\end{array}$ & Fernández y Costa 2004 & Nivel de uso \\
\hline Sa Cala & KIA-20215 & $2565 \pm 25$ & $\begin{array}{l}\text { 797-771 } \\
\text { cal ANE }\end{array}$ & $\begin{array}{l}806-590 \\
\text { cal ANE }\end{array}$ & Fauna & Canis & Ramón y Colomar 1999 & Nivel de uso \\
\hline Sa Cala & KIA-20222 & $2560 \pm 25$ & $\begin{array}{l}798-766 \\
\text { cal ANE }\end{array}$ & $\begin{array}{l}805-569 \\
\text { cal ANE }\end{array}$ & Fauna & UE-606 & Ramón y Colomar 1999 & Nivel de uso \\
\hline
\end{tabular}

Tab. 1. Dataciones radiométricas de la Prehistoria pitiusa, calibradas con el programa OxCal (v.4.2.) (Bronk Ramsey 2013) con la curva IntCal13 (Reimer et al. 2013).

que han contribuido a la configuración de esta realidad. Predominan los contextos excavados sin dataciones radiocarbónicas (Tab. 1). Esta incertidumbre cronológica ha contribuido a que la mayoría de los marcos cronoculturales aplicados a las primeras poblaciones de estas islas tuvieran su punto de partida en los tradicionalmente más contrastados de los grupos arqueológicos y periodizaciones de las islas de Mallorca y Menorca. grupos de filiación campaniforme) les sucedieron otros con características materiales propiamente baleáricas, conocidos especialmente por sus habitaciones naviformes ${ }^{1}$. Las propuestas crono-

\footnotetext{
${ }^{1}$ Entendemos por naviformes aquellas estructuras de planta de nave invertida o herradura, cierre absidal o apuntado, construidas a partir de muros de estructura tripartita, que dan nombre a los periodos Medio y Final de la Edad del Bronce en Baleares, según la terminología clásica.
} 
lógicas más aceptadas (Micó 2005; ${ }^{2}$ ) sitúan su funcionamiento entre $c a .1600 / 1450$ y $900 / 850 \mathrm{cal}$ ANE, siguiendo los planteamientos de una primera propuesta (Lull et al. 1999), en su momento decisiva para la ordenación temporal del naviforme y la prehistoria balear. No obstante, algunas de las fechas atribuidas a este grupo arqueológico mantienen el debate cronológico abierto, por lo que deben considerarse con prudencia. Se trata de las procedentes del yacimiento de Arenalet de Son Colom (Ramis et al. 2007), cuyo carácter naviforme se discute, y del Hospitalet Vell, con varias fechas envueltas en los problemas del laboratorio de Kiel (Lull et al. 2015).

Las recientes excavaciones en Cap de Barbaria II, partiendo de esta propuesta de periodización (Micó 2005: 430-432), han permitido defender la inclusión del yacimiento en el grupo arqueológico naviforme (Sureda et al. 2013; ${ }^{3}$ ). Se trata de sus primeras evidencias en las Pitiusas y, como veremos, las dataciones radiocarbónicas presentadas en este artículo, resultan relevantes para la comprensión de todo el periodo. A la vez, este trabajo resuelve algunas dudas planteadas sobre la presencia de población estable en las islas Pitiusas durante el Bronce Final (Gómez Bellard y San Nicolás 1988; Gómez Bellard 2003; Dawson 2010), aspectos también relevantes al considerar los fenómenos de expansión territorial que culminan con el establecimiento de los primeros colonos fenicios en el archipiélago (Ramón 2007).

\section{CONTEXTUALIZACIÓN Y MÉTODO}

\subsection{El poblado de Cap de Barbaria II (Formentera)}

Cap de Barbaria II (CBII) es un poblado al aire libre de unos $1.500 \mathrm{~m}^{2}$ de superficie, localizado en el extremo suroeste de la isla de Formentera

\footnotetext{
${ }^{2}$ Calvo, M.; Javaloyas, D.; Albero, D. J.; García Roselló, J. y Fornés, J. "Radiocarbon dates of Balearic Bronze Age Naviforms: critical review and new approaches". Poster en7th International Symposium "C14 and archaeology" (Gante, Bélgica 2013).

${ }^{3}$ Sureda, P. 2016: Les comunitats prehistòriques pitiüses $i$ la seva interacció social: aportacions des de l'arqueometal·lúrgia $i$ els espais domèstics. Tesis doctoral, Universitat Pompeu Fabra. Barcelona.
}

(UTM 31N ETRS89: X 361093, Y 4280237), a unos $87 \mathrm{~m}$ s.n.m. Forma parte de un conjunto de, al menos, 21 yacimientos similares, situados sobre el promontorio que recibe el mismo nombre (Fig. 1). El yacimiento fue parcialmente excavado entre 1979 y 1987 por investigadores del Museo Arqueológico de Ibiza y Formentera (Topp et al. 1979; Fernández y Topp 1984; Costa y Fernández 1992) y desde el año 2012 se desarrolla en él un nuevo proyecto arqueológico de carácter interdisciplinar (Sureda et al. 2013; ${ }^{4}$; López-Dóriga et al. 2015; Sureda et al. 2017).

En el poblado se distinguen dos momentos constructivos: la 'Fase 1', con muros de ortostatos verticales y la 'Fase 2', que recoge un conjunto de reestructuraciones y compartimentaciones con muros a una y dos caras de hiladas horizontales de piedra. Se accedía mediante tres entradas que daban paso a nueve espacios o habitaciones diferenciadas, que llamamos 'Ámbitos'. Destacan los Ámbitos 7, 8 y 9, que presentan una planta de tipo naviforme y, probablemente, acogieron el conjunto de actividades domésticas que reflejan las evidencias arqueológicas: hogares, banquetas, enlosados y cubetas de almacenamiento (Fig. 2).

Los 6 restantes del poblado $(1,2,3,4,5$ y 6) tienen diferentes plantas (circular, semicircular y oval alargada) y pudieron servir de base a actividades económicas como la talla del sílex y de la caliza, la fundición de metales de cobre y bronce, la producción de recipientes de cerámica, el almacenamiento de víveres (agua y cereales), la estabulación de rebaños, o funcionar en parte como basureros.

Se ha propuesto que sus pobladores basaran su subsistencia en la agricultura (trigo, cebada, panizo), la ganadería (caprina, bovina, porcina), la caza de algunas aves, la pesca y la recolección de moluscos marinos (principalmente lapas y caracolillos) (Sureda et al. 2017). A partir de los datos arqueológicos se ha sugerido que se organizaron socialmente de una manera relativamente igualitaria y en colaboración con el resto de comunidades de su entorno ${ }^{5}$. También mantuvieron contactos puntuales con otras comunidades del Mediterráneo, de donde obtenían los recursos minerales ausentes en Formentera como el sílex, el cobre o el estaño.

\footnotetext{
4 Véase n. 3.

5 Véase n. 3.
} 


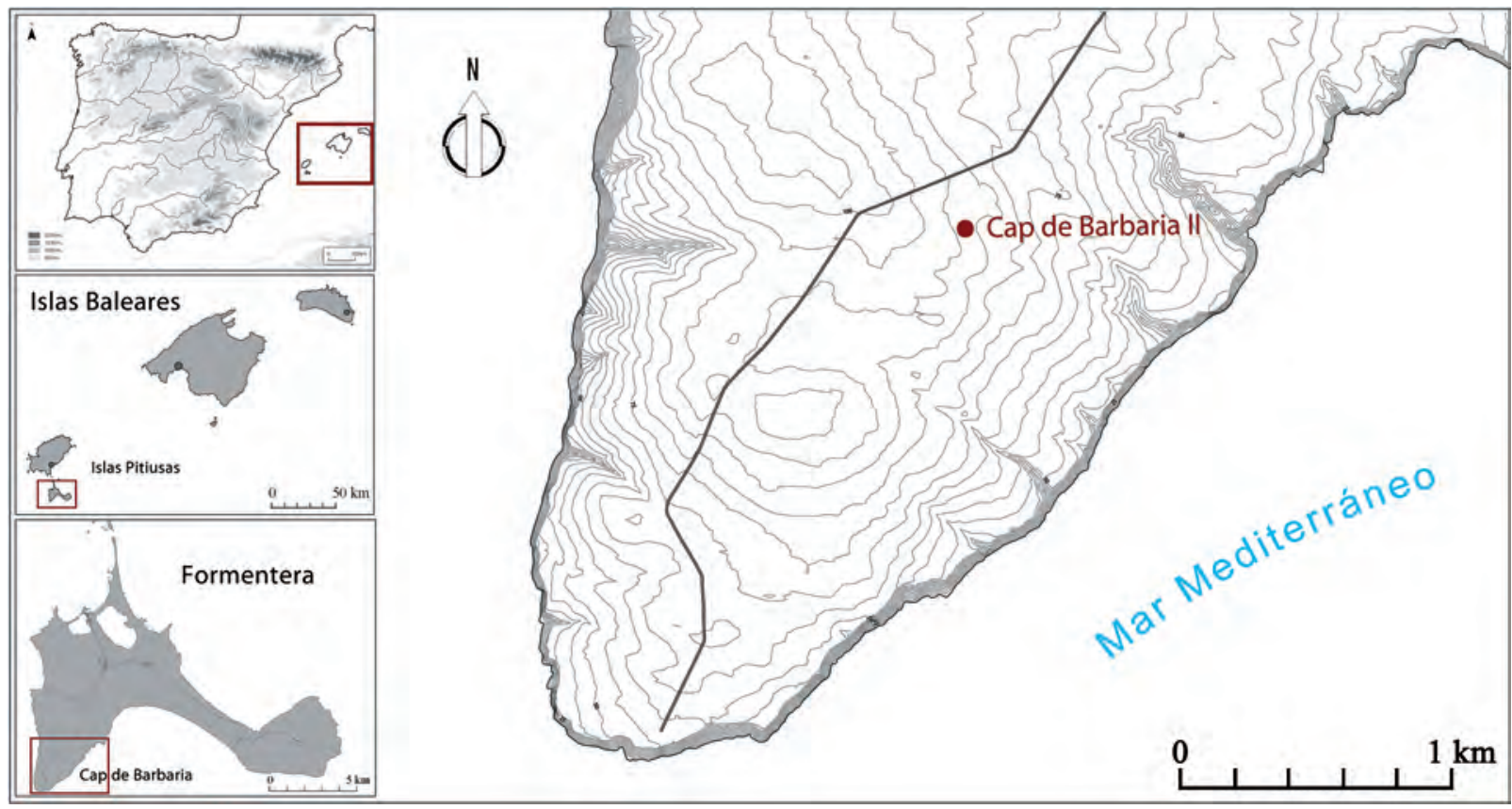

Fig. 1. Localización de Cap de Barbaria II (Formentera, islas Pitiusas, Islas Baleares). En los mapas de Formentera se incluye la red de carreteras. Base cartográfica: hoja digital 849 del MTN25 vectorial del IGN (separación de curvas de nivel: $5 \mathrm{~m}$ ).

Actualmente, gran parte de los materiales exhumados está en estudio y, a priori, no existen grandes diferencias entre las dos fases arquitectónicas. Se ha planteado una primera caracterización de algunas estructuras como el Ámbito 9 (Sureda et al. 2013), se han avanzado algunos datos relativos al registro arqueobotánico (LópezDóriga et al. 2015) y se ha propuesto una estrategia adaptada de subsistencia y explotación de los recursos locales disponibles (Sureda et al. 2017). En este último trabajo se avanzaron los resultados de dos dataciones radiocarbónicas (RICH-20967 y MAMS-22644).

\subsection{Estrategia de recogida de muestras y su contexto estratigráfico}

Las campañas de excavación realizadas a partir de 2012 han proporcionado un conjunto de materiales arqueológicos sobre los que se ha planteado una estrategia sistemática de datación numérica para la acotación cronológica de la ocupación del poblado y sus distintas fases. La selección de muestras para fechar los distintos contextos ha priorizado que fueran altamente representativas de los acontecimientos documentados en el poblado y que identificamos a nivel arquitectónico y arqueológico (construcción de estructuras, momentos de ocupación, transformación/reestructuración o abandono). Todas las muestras recogidas proceden de las estructuras de planta naviforme (Fig. 3).

Especialmente representativo de las dinámicas constructivas de CBII es el Ámbito 9 (Fig. 4), que centró las campañas de excavaciones de 2012 y 2014, y donde se diferenciaron dos estructuras naviformes superpuestas (Sureda et al. 2013). La estructura de la Fase 1 tiene planta de tipo naviforme de tendencia 'triangular', o el ábside apuntado. Está construida a partir de muros con doble línea de ortostatos verticales, muy mal conservados. En su interior destaca una estructura de combustión semicircular y enlosada, definida por la UE 1.9.9.1. Una capa de tierra pisada de color marrón claro y arcilloso conforma su suelo de ocupación (UE 1.9.1.3). De él proceden las muestras RICH20970 y RICH-20971 (falange y metatarso de Caprinae respectivamente) y la muestra OxA-31927 

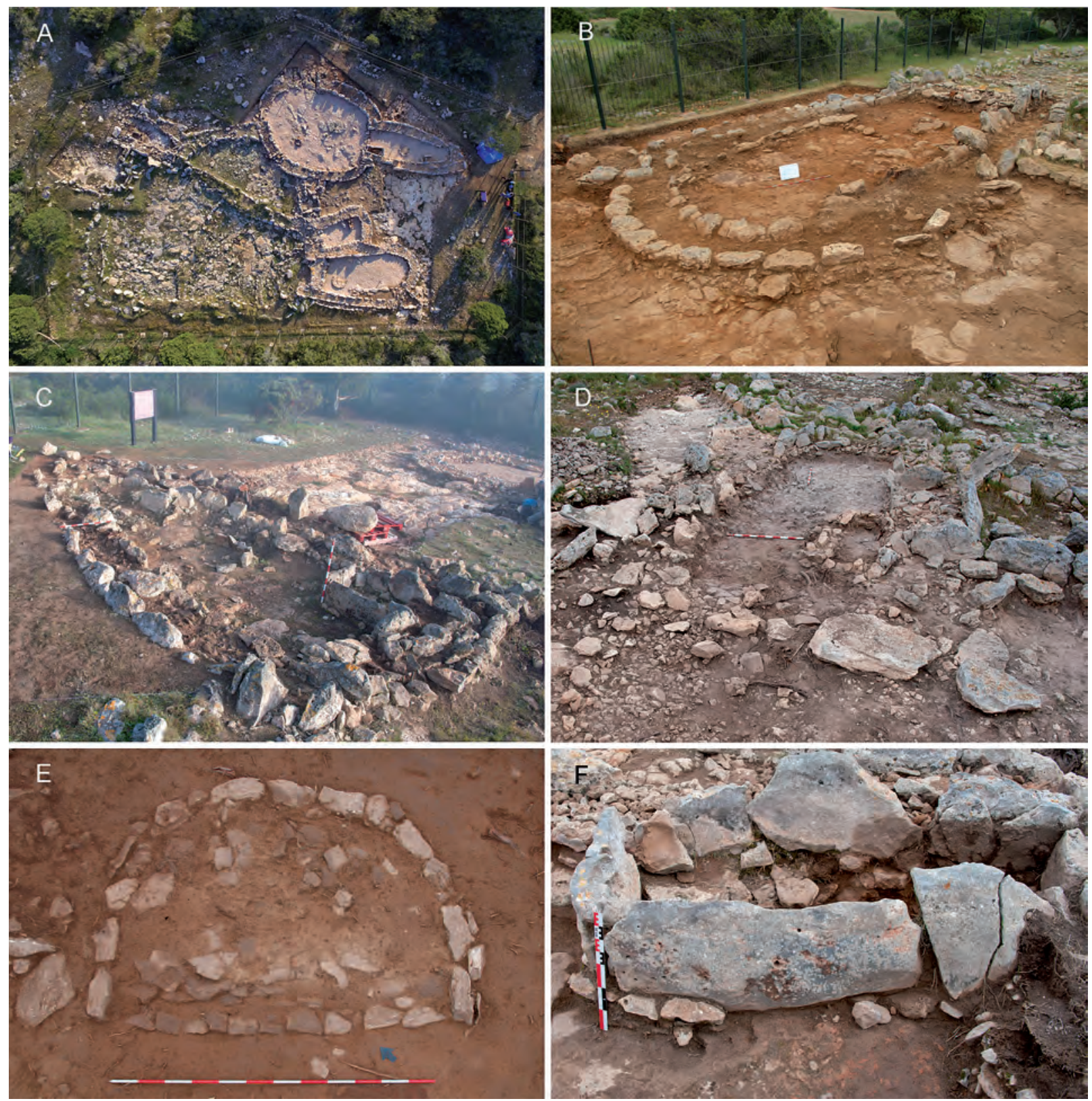

Fig. 2. Cap de Barbaria II (Formentera, Islas Baleares): A. Vista aérea del poblado (abril de 2016); B. Naviforme del Ámbito 9; C. Naviforme del Ámbito 7; D. Naviforme del Ámbito 8; E. Estructura de combustión con enlosado del Ámbito 9; F. Estructura de almacenaje del Ámbito 7 (en color en la edición electrónica).

(gasterópodo de la especie Phorcus turbinatus). Esta UE 1.9.1.3, vinculada directamente al uso de la estructura como espacio doméstico, cubría una capa de preparación del suelo (UE 1.9.1.4), cuya formación fue posiblemente contemporánea a la construcción del naviforme. De ella proviene la muestra RICH-20967 de hueso largo de Capri- nae. Por otra parte, un muro cierra la entrada al sur del naviforme y cubre parte de las anteriores unidades estratigráficas (UE 1.9.1.3 y 1.9.1.4). En un sondeo en su interior se distinguió la UE 1.9.2.4, considerada equivalente a la UE 1.9.1.3. De ella procede la datación MAMS-22644 sobre un molar de Caprinae. 


\section{A}

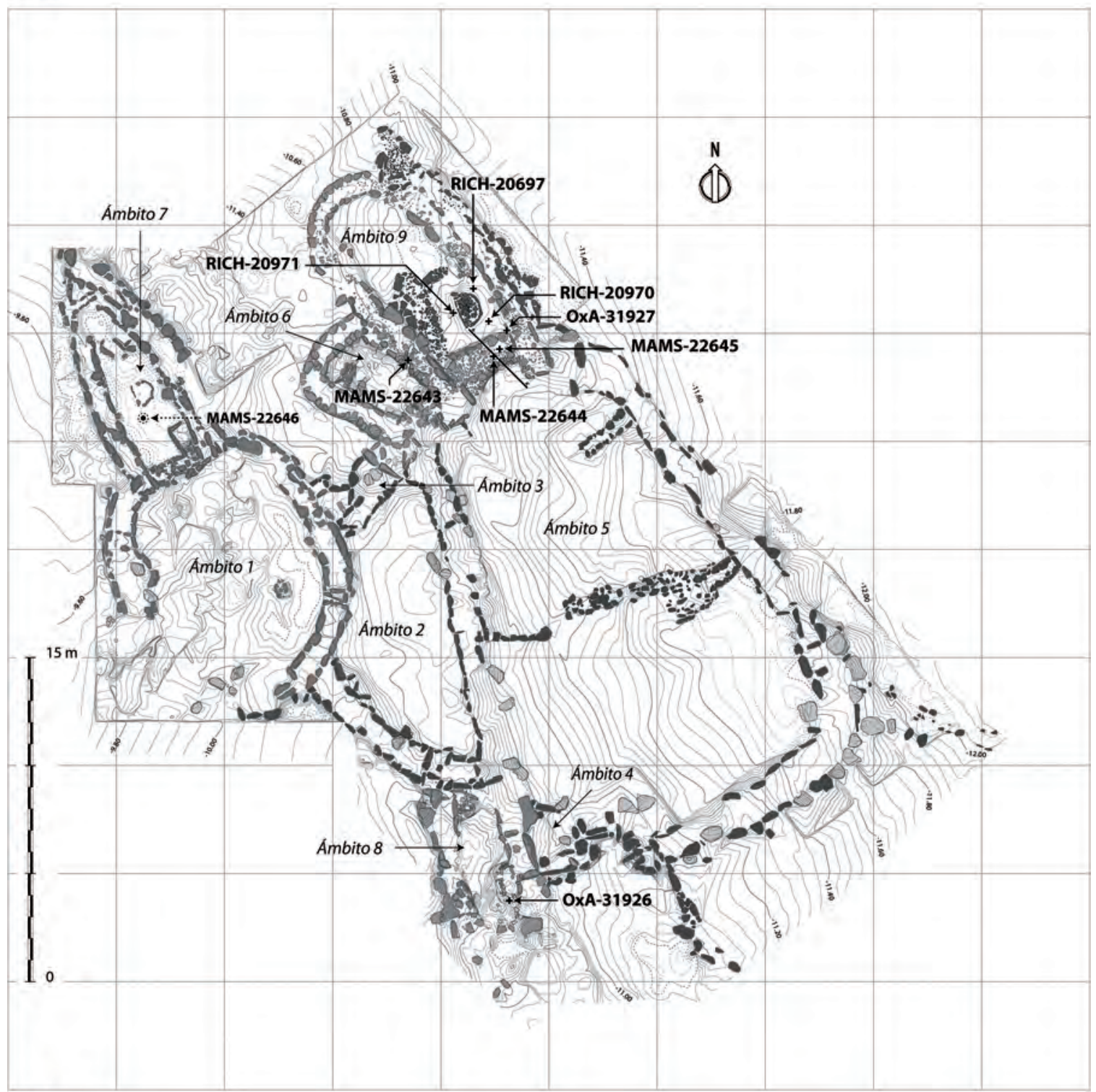

B

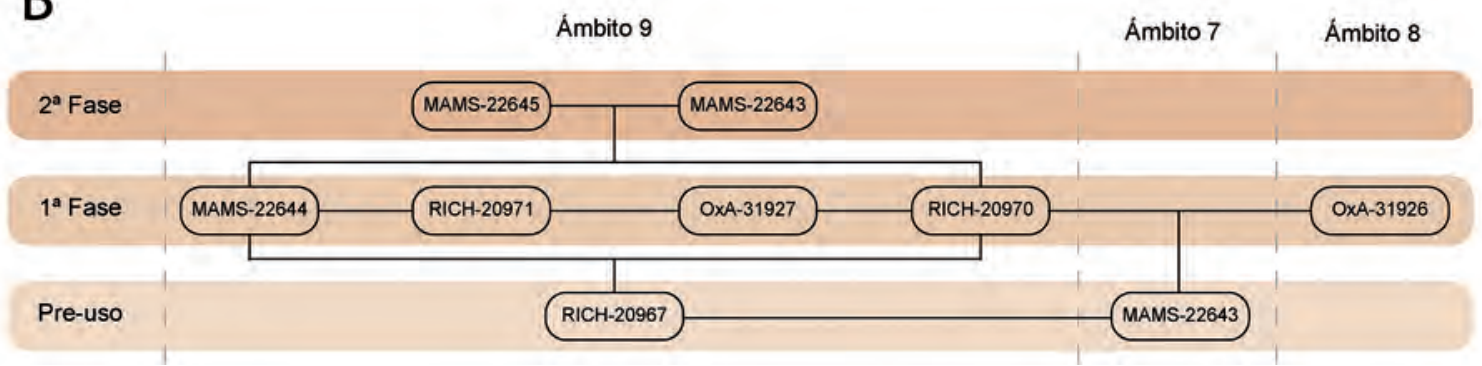

Fig. 3. Cap de Barbaria II (Formentera, Islas Baleares): A. Planta con la distribución espacial de muestras seleccionadas para la datación. La línea discontinua refiere a una muestra localizada en base a su UE; B. Gráfico con las relaciones estratigráficas de dichas muestras, atendiendo a las fases constructivas y a la estructura naviforme a la que corresponden.

Trab. Prehist., 74, N. ${ }^{\circ} 2$, julio-diciembre 2017, pp. 319-334, ISSN: 0082-5638 doi: $10.3989 /$ tp.2017.12197 


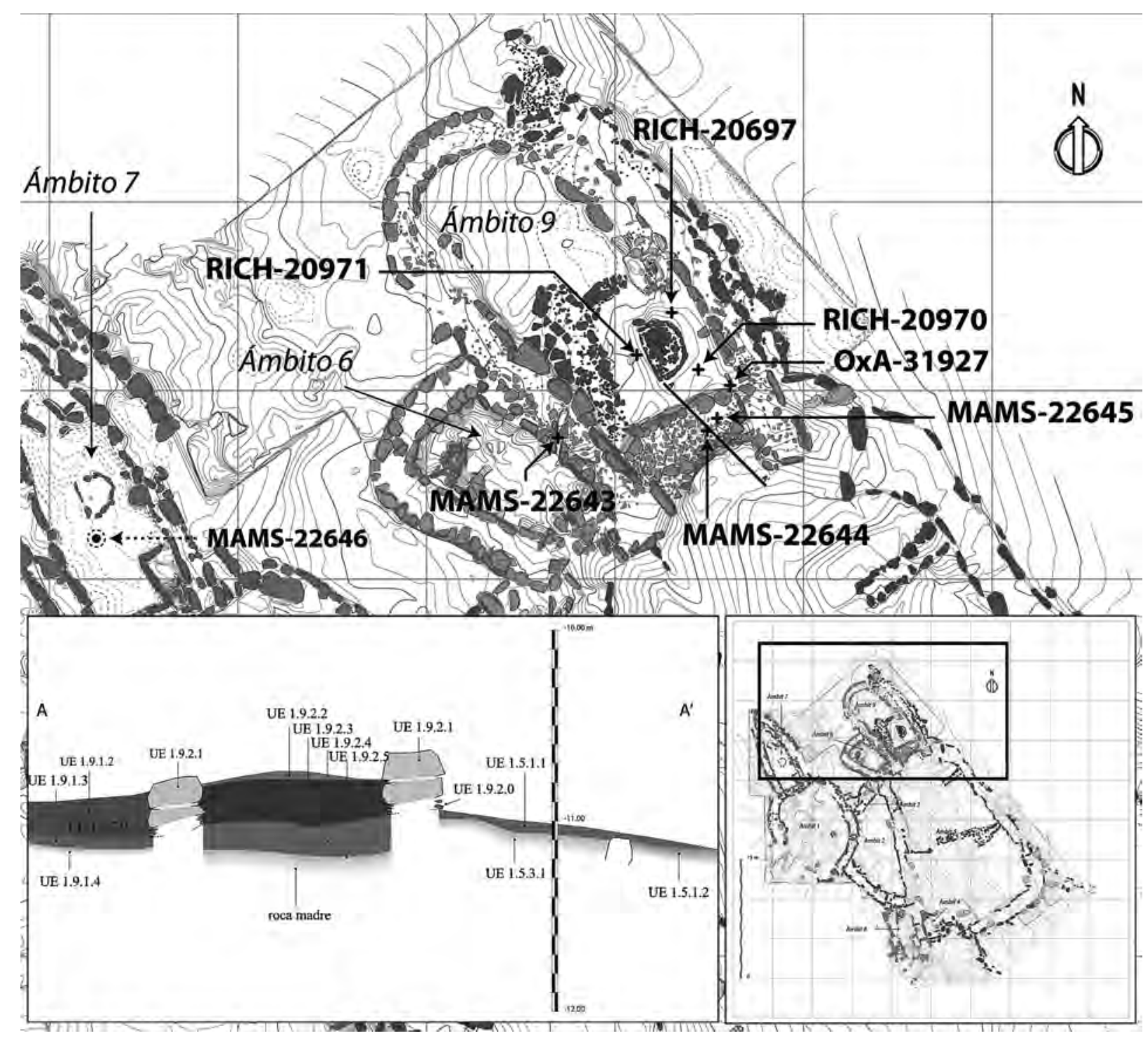

Fig. 4. Planta del Ámbito 9 de Cap de Barbaria II (Formentera), mostrando la principal secuencia arquitectónica: 'Fase 1' (oscura) y 'Fase 2' (clara), así como la sección estratigráfica sobre el muro sur.

La planta de la estructura naviforme de la Fase 2 es más alargada. La definen muros de ortostatos (este y oeste) y un cierre más oval gracias a muros de hiladas de piedras (norte y sur) que son posteriores. Destaca la presencia de un banco lateral (UE 1.9.6.1) adosado al muro este, junto al cual hay un receptáculo (UE 1.9.15.1) sobre el que se depositó un gran recipiente. Lamentablemente, la unidad estratigráfica correspondiente al último momento de uso o de abandono (UE 1.9.1.2) del interior de esta estructura naviforme estaba muy alterada por procesos tafonómicos.
Entre los Ámbitos 9 y 6 un pequeño receptáculo, delimitado por dos losas (UE 1.9.17.1), conformaba una estructura inter-muraria cuya funcionalidad exacta desconocemos. Del relleno (UE 1.9.17.2) procede la muestra MAMS-22643 (húmero de Caprinae). Otra muestra asociada a esta Fase 2 es MAMS-22645 (hueso de Caprinae), procedente del sondeo en el muro de cierre de acceso, la estructura más reciente de las documentadas en este Ámbito, y que se atribuye al relleno del mismo (UE 1.9.2.3). Con ella se pretendía obtener una fecha ante quem de la construcción de dicha estructura. 
La muestra MAMS-22646 (metatarso de Caprinae) procede de la UE "Nivel 3", según la nomenclatura de las excavaciones de 1986 en el Ámbito 7; corresponde a una capa previa a la construcción de otra de las estructuras naviformes de CBII. La capa se define como arcillosa y amarillenta y posee unos $15-20 \mathrm{~cm}$ de espesor. La muestra OxA-31926 (concha de P. turbinatus) corresponde a la UE 2.8.1.3, que es el suelo de ocupación del Ámbito 8, la tercera estructura naviforme documentada en el poblado. Es una capa de composición arcillosa rojiza, oscurecida por los restos de carbones procedentes del hogar central de la habitación.

\subsection{Calibración y análisis bayesiano de los resultados}

Todas las muestras de fauna analizadas corresponden a huesos de mamíferos domésticos y se han datado por espectrometría de masas con acelerador (AMS) en los laboratorios del Institut Royale du Patrimoine Artistique (Bruselas), y del Klaus-Tschira-Archäometrie-Zentrum de la Universidad de Heidelberg (Mannheim, Alemania). En los laboratorios de la Universidad de Oxford (Reino Unido) se dataron las dos muestras malacológicas de conchas del caracol marino Phorcus turbinatus.

Todas las dataciones se han calibrado utilizando el software OxCal v.4.2 (Bronk Ramsey 2009), con la curva IntCal13 para las muestras sobre restos de fauna terrestre y la curva Marine13 (Reimer et al. 2013) para las muestras de origen marino. El intervalo de confianza que hemos tenido en cuenta normalmente corresponde a una probabilidad del

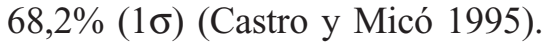

La calibración de las muestras de concha ha tenido en consideración el efecto reservorio marino del radiocarbono (Mangerud 1972). Desafortunadamente, faltan en este momento valores de $\Delta \mathrm{R}$ metodológicamente firmes (misma especie de molusco marino, misma época, misma región y mismo tipo de alimentación e incorporación de carbono a su organismo) que se puedan aplicar a nuestras muestras. En este caso hemos optado por tomar el valor $\Delta \mathrm{R} 26 \pm 24$, obtenido en conchas de múrex (Hexaplex trunculus) para la Isla de Mallorca en época tardorromana (Van Strydonck et al. 2010), por ser el valor que consideramos más apropiado de entre las opciones disponibles. En el Mediterráneo Occidental existen datos de $\Delta \mathrm{R}$ de moluscos marinos procedentes de Banyuls (España), Castiglione, Alger y Cherchel (Argelia) y Marsella (Francia), todos ellos fechados en el I milenio DNE (Siani et al. 2000; Reimer y McCormac 2002) cuyo valor medio ponderado $\Delta \mathrm{R}$ (83 \pm 57 ) (Bevington 1969) incluye los datos mallorquines utilizados en nuestro caso de estudio, en los márgenes de la desviación típica para la región. Además, la escasa profundidad del mar Mediterráneo en torno a las islas Baleares supone la existencia de una mínima surgencia de aguas antiguas (Van Strydonck et al. 2010). Todos estos motivos hacen suponer que el valor $\Delta \mathrm{R}$ que hemos utilizado tiene un grado de fiabilidad relativamente elevado.

Se ha llevado a cabo un análisis bayesiano de las dataciones radiocarbónicas con el fin de trabajar conjuntamente con las diferentes probabilidades de cada una. El análisis proporciona estimaciones para el inicio y fin de un evento arqueológico, combinando las probabilidades estandarizadas de múltiples fechas con otras informaciones cronológicas de carácter relativo, en nuestro caso, estratigráficas y arquitectónicas. Para ello hemos considerado tres fases concernientes a la vida útil de los naviformes de CBII: las fases arquitectónicas 1 y 2, ya descritas, y una fase 'Pre-uso' identificada estratigráficamente. De cara al modelado bayesiano, todas las fases (Pre-uso, Fase 1 y Fase 2), se tratan como tres "Fases" contiguas ordenadas en una "Secuencia" cronológica (Phases, Contiguous) y separadas por límites de transición (Boundary) y un posible hiato (Interval) entre la Fase 1 y la Fase 2 (Buck et al. 1992; Bayliss et al. 2007; Bronk Ramsey 2009).

\section{RESULTADOS}

\subsection{Las dataciones radiocarbónicas y su análisis bayesiano}

De las 9 muestras para datación presentadas, 6 han proporcionado resultados positivos y 3 no han podido fecharse por falta de colágeno. A continuación se exponen los resultados calibra-

Trab. Prehist., 74, N. ${ }^{\circ}$ 2, julio-diciembre 2017, pp. 319-334, ISSN: 0082-5638

doi: $10.3989 /$ tp.2017.12197 


\begin{tabular}{|l|c|c|c|c|c|c|c|c|}
\hline \multicolumn{1}{|c|}{ Código Lab. } & UE & Material & Edad (BP) & $\begin{array}{c}\text { Cal ANE } \\
(\mathbf{2} \sigma)\end{array}$ & $\begin{array}{c}\text { Cal ANE } \\
(\mathbf{1} \sigma)\end{array}$ & ${ }^{13} \mathbf{C}$ & C:N & Contexto \\
\hline MAMS-22645 & 1.9 .2 .3 & Indeterminable & - & - & - & - & - & Fase 2, uso \\
\hline MAMS-22643 & 1.9 .17 .2 & Húmero (Caprinae) & $2802 \pm 23$ & $1011-901$ & $992-919$ & $-23,8$ & 3 & Fase 2, uso \\
\hline MAMS-22644 & 1.9 .2 .4 & Molar (Caprinae) & $3308 \pm 23$ & $1641-1516$ & $1621-1534$ & $-17,9$ & 2,2 & Fase 1 , uso \\
\hline OxA-31927 & 1.9 .1 .3 & Phorcus turbinatus & $4420 \pm 28$ & $2736-2469$ & - & 3,1 & - & Fase 1 , uso \\
\hline RICH -20970 & 1.9 .1 .3 & Falange 1a (Caprinae) & - & - & - & - & - & Fase 1 , uso \\
\hline RICH -20971 & 1.9 .1 .3 & Metatarso (Caprinae) & - & - & - & - & - & Fase 1 , uso \\
\hline OxA-31926 & 2.8 .1 .3 & Phorcus turbinatus & $3950 \pm 28$ & $2102-1857$ & - & 2,2 & - & Fase 1 , uso \\
\hline MAMS-22646 & Nivel 3 & Metatarso (Caprinae) & $3378 \pm 23$ & $1741-1621$ & $1691-1636$ & $-19,7$ & - & Fase 1 , pre-uso \\
\hline RICH-20967 & 1.9 .1 .4 & Hueso largo (Caprinae) & $3287 \pm 33$ & $1643-1497$ & $1611-1530$ & -21 & 3,3 & Fase 1 , pre-uso \\
\hline
\end{tabular}

Tab. 2. Resumen de las dataciones de carbono 14 de Cap de Barbaria II (Formentera, Islas Baleares).

\begin{tabular}{|c|c|c|c|c|c|c|c|c|c|c|c|c|}
\hline & \multicolumn{6}{|c|}{ Sin Modelar (cal ANE) } & \multicolumn{6}{|c|}{ Modelado (cal ANE) } \\
\hline & desde & hasta & $\%$ & desde & hasta & $\%$ & desde & hasta & $\%$ & desde & hasta & $\%$ \\
\hline Límites Fin 2 & & & & & & & -994 & -728 & 68,2 & -1024 & -137 & 95,4 \\
\hline R_Date MAMS-22643 & -992 & -919 & 68,2 & -1011 & -901 & 95,4 & -997 & -927 & 68,2 & -1016 & -901 & 95,4 \\
\hline \multicolumn{13}{|l|}{ Fase 2} \\
\hline Función «Interval’ & & & & & & & 0 & 638 & 68,2 & 0 & 642 & 95,4 \\
\hline Límites Transición 1/2 & & & & & & & -1586 & -958 & 68,2 & -1591 & -951 & 95,4 \\
\hline R_Date MAMS-22644 & -1621 & -1534 & 68,2 & -1641 & -1516 & 95,4 & -1580 & -1531 & 68,2 & -1618 & -1513 & 95,4 \\
\hline \multicolumn{13}{|l|}{ Fase 1} \\
\hline Límites Transición Pre-Uso/1 & & & & & & & -1624 & -1558 & 68,2 & -1656 & -1533 & 95,4 \\
\hline R_Date MAMS-22646 & -1692 & -1636 & 68,2 & -1741 & -1621 & 95,4 & -1674 & -1626 & 68,2 & -1732 & -1614 & 95,4 \\
\hline R_Date RICH-20967 & -1611 & -1530 & 68,2 & -1643 & -1497 & 95,4 & -1641 & -1583 & 68,2 & -1681 & -1560 & 95,4 \\
\hline \multicolumn{13}{|l|}{ Fase Pre-Uso } \\
\hline Límites Inicio Pre-Uso & & & & & & & -1737 & -1629 & 68,2 & -1991 & -1612 & 95,4 \\
\hline Secuencia & & & & & & & & & & & & \\
\hline
\end{tabular}

Tab. 3. Rangos de distribución de probabilidades de los resultados de la calibración de las cuatro dataciones de Cap de Barbaria II (Formentera, Islas Baleares) y límites generados por el modelado bayesiano para su secuencia de ocupación. 


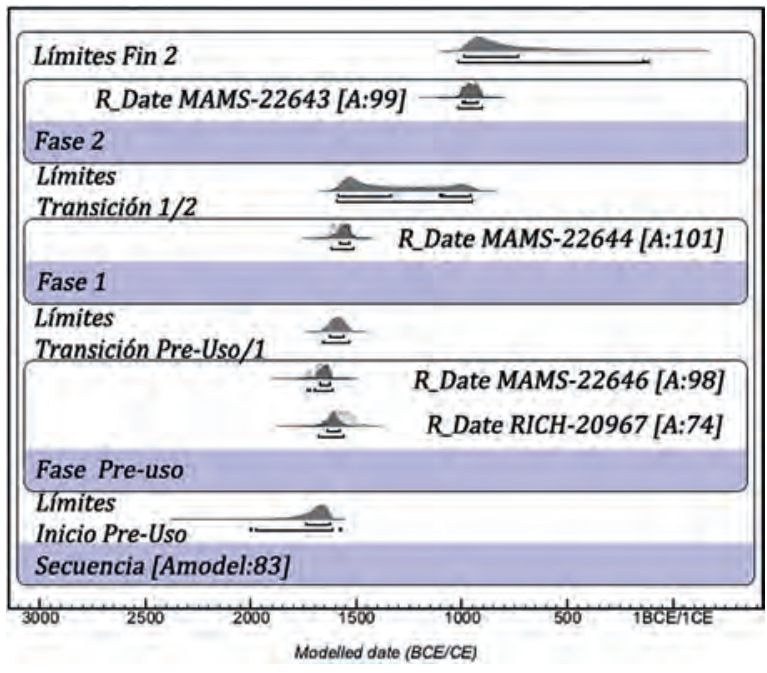

Fig. 5. Modelado bayesiano a partir de las muestras de carbono 14 sobre hueso del poblado de Cap de Barbaria II (Formentera, Islas Baleares), calibradas con el programa OxCal (v.4.2.) (Bronk Ramsey 2013) con la curva IntCal13 (Reimer et al. 2013).

dos (Tab. 2) y las reflexiones relativas a la interpretación de las fechas, así como el modelado bayesiano de las mismas (Fig. 5, Tab. 3). Debido a la distinta fiabilidad de la calibración de los resultados, trataremos por separado las realizadas sobre hueso y sobre concha.

\subsection{Los contextos fechados con muestras de hueso}

La fecha MAMS-22646 aporta un intervalo (calibrado y modelado) de 1732 a 1614 cal ANE a $2 \sigma$ y de 1674-1626 cal ANE a $1 \sigma$. Es la datación más antigua y permite situar la primera presencia humana en la zona con anterioridad a $1614 \mathrm{cal}$ ANE $(2 \sigma)$ o a 1626 cal ANE $(1 \sigma)$. Sin embargo, al tratarse de una preparación o pavimentación del terreno, esta no se relaciona con el uso del naviforme o Ámbito 7, sino con alguna actividad anterior o, a lo sumo, con su momento de construcción. De hecho, esta datación sugiere que la construcción de la preparación, y por extensión del Ámbito 7, es necesariamente posterior a 1732 cal ANE, sin poder precisar más por el momento.

MAMS-22644 está en el intervalo 1618-1513 cal ANE a $2 \sigma$ y $1580-1531$ cal ANE a $1 \sigma$ y per- mite asignar la construcción y uso del naviforme (Fase 1, Ámbito 9) con anterioridad a $1513 \mathrm{cal}$ ANE $(2 \sigma)$ o a 1531 cal ANE $(1 \sigma)$. Por otra parte, dada su procedencia, también hace posible situar los momentos de reestructuración del naviforme, mediante la construcción del muro sur, con posterioridad a la fecha mencionada, sin poder precisar más por ahora. Lamentablemente, la datación procedente del relleno de este mismo muro (MAMS 22645), que habría podido acotarlo, no dispuso de suficiente colágeno.

RICH-20967 se sitúa en el intervalo 16811560 cal ANE a $2 \sigma$ y $1641-1583$ cal ANE a $1 \sigma$, y resulta muy cercana a MAMS 22644. Creemos que su incorporación al registro responde a un mismo momento, que a la vez permite situar la construcción y el inicio del uso del naviforme (Fase 1, Ámbito 9) en este caso con anterioridad a 1560 cal ANE $(2 \sigma)$ o a 1583 cal ANE ( $1 \sigma)$.

MAMS-22643 queda en el intervalo 1016901 cal ANE a $2 \sigma$ y $997-927$ cal ANE a $1 \sigma$, lo que la aleja de las anteriores. Se incorpora al registro cuando tanto el muro (atribuido a la Fase 2) como el receptáculo estaban aún en uso. La datación logra asignar la reconstrucción del naviforme (Fase 2, Ambito 9) a un momento necesariamente anterior a $927 \mathrm{cal}$ ANE y al propio abandono del poblado en fechas posteriores

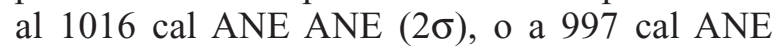
$(1 \sigma)$, sin que ambos hechos puedan precisarse más en el tiempo.

\subsection{Los contextos fechados con muestras de concha}

Dos muestras de concha de Phorcus turbinatus han podido fecharse en el laboratorio de la Universidad de Oxford. La primera fecha, OxA31926, se sitúa en el intervalo 2819-2472 cal ANE a $2 \sigma$, resultando alejada de las que hemos visto antes. Su incorporación al registro hace referencia a un momento en que el naviforme del Ámbito 8 estaba en uso. La segunda fecha, OxA-31927, corresponde a los niveles de uso del Ámbito 9. La datación obtenida se sitúa en el intervalo 21261851 cal ANE a $2 \sigma$, igualmente alejada de las fechas obtenidas sobre muestras de hueso en niveles estratigráficamente contemporáneos (MAMS22644 y RICH-20967). 
Estos dos resultados, por ser notablemente dispares con respecto a las muestras de huesos de mamíferos de los mismos episodios datados, quedan excluidos del modelado de los resultados de las dataciones. La disparidad de estos resultados puede deberse a los problemas relacionados con la calibración de muestras de moluscos marinos (Mangerud 1972) y a las dificultades en estimar el efecto reservorio local con precisión (p.e. LópezDóriga 2014).

No es probable que las conchas fueran recogidas en la playa después de haber muerto los animales, ya que las superficies de ambas carecían de alteraciones características, como la erosión, a causa del agua marina y del entorno arenoso, y a la presencia de organismos incrustantes en el interior. Además, Phorcus turbinatus es una de las especies con interés bromatológico más abundantes documentadas en las diferentes fases del yacimiento. Es posible que las fechas estén artificialmente envejecidas por algún efecto de diagénesis. De cualquier modo, este motivo desaconseja tener en consideración, por el momento, los resultados sobre conchas para la discusión de los datos.

\section{LA SECUENCIA DE OCUPACIÓN EN CBII Y EL NAVIFORME BALEAR}

Señalamos al introducir este trabajo el debate científico en torno al grupo arqueológico naviforme y, en especial, a su cronología. En líneas generales, se barajan dos opciones a partir de los restos de S'Arenalet de Son Colom y sus dataciones KIA-26215 y KIA-26226, comprendidas entre ca. 2100 y 1950 cal ANE (Ramis et al. 2007), como las primeras evidencias de este grupo.

Parece haber un mayor acuerdo en situar el techo superior del periodo naviforme entre ca.1500/1450 cal ANE (Micó 2005; ${ }^{6}$ ), aunque el origen de la arquitectura ciclópea y la construcción de los primeros naviformes podría ser ligeramente anterior (ca.1600 cal ANE). Del mismo modo, se sitúa entre $c a .1450$ y 1100/1000 cal ANE un momento de expansión territorial y estabilidad en las relaciones sociales de estas comunidades. Este se

${ }^{6}$ Véase n. 2. traduce en una gran homogeneidad en sus manifestaciones materiales, abrazando la totalidad del territorio mallorquín y menorquín con numerosos ejemplos como los de Alemany (Enseñat 1971; Calderón et al. 2014), Hospitalet Vell (RossellóBordoy 1983; Ramis y Salas 2014), Canyamel (Rosselló-Bordoy y Camps 1972), Clariana (Plantalamor y Anglada 1978), Cala Morell (Anglada et al. 2013) o Cala Blanca (Juan y Plantalamor 1997). Finalmente, desde el fin de esta fase y hasta el ca. 900/850 cal ANE, tal y como se constata en Closos y Son Baduia, las sociedades naviformes experimentarían un conjunto de transformaciones (también conocido como periodo "Prototalayótico") que culminaría en su abandono definitivo para dar lugar a formaciones socioeconómicas diferentes.

Las investigaciones efectuadas en CBII no permiten resolver este debate, aunque sí constatar la ocupación del lugar entre ca. 1650 y 900 cal ANE con 2 fases constructivas diferenciadas. Veamos ahora con más detalle las implicaciones concretas que se desprenden de cada una de estas constataciones, partiendo de los datos obtenidos en el modelo.

El primer hecho que podemos poner de relieve es que hubo un poblamiento previo en la zona, tal vez relacionado con alguno de los naviformes cercanos a CBII. Este momento pudo empezar en el intervalo 1737-1629 cal ANE ('Límite Inicio Pre-Uso') y es previo a la construcción de los Ámbitos 7 y 9 de CBII.

En segundo lugar, la transición entre la fase Pre-uso y la Fase 1 ('Límite Transición PreUso/1') determina el posible momento de construcción de los naviformes de la Fase 1 (16241558 cal ANE). Este intervalo surge al considerar los datos procedentes de las dataciones MAMS22646 y MAMS-22644, que establecen un término ante quem para la construcción del Ámbito 7 y otro post quem para la Fase 1 del Ámbito 9. Este intervalo concuerda con los datos de construcción propuestos para los naviformes del resto de Baleares (ca. 1600-1450 cal ANE). Sin embargo, hasta hace poco, varios autores defendían la existencia de un momento incipiente del periodo naviforme, llamado Naviforme I, con inicio en $c a .1700 \mathrm{cal}$ ANE, basado en varias dataciones procedentes de los niveles inferiores de los naviformes Alemany, Son Ferrandell y Naviforme 1 de Closos de Can Gaià (p.e. Salvà y Hernández-Gasch 2009). La 
revisión reciente de estos niveles ha motivado la sustitución de esta propuesta cronológica en favor de una rebaja sustancial de este techo cronológico, que actualmente sitúan ca. 1500/1400 cal ANE para la construcción de los primeros naviformes ${ }^{7}$. De poder acotar más este intervalo para CBII en el futuro, habría que valorar la posibilidad de que las primeras construcciones naviformes de Formentera fueran ligeramente anteriores a las del resto de Baleares. No obstante, de momento no creemos que se correspondan con el modelo de cronología alta propuesto a partir de S'Arenalet de Son Colom (Plantalamor 1991; Ramis et al. 2007).

En tercer lugar, podemos situar el primer momento de uso (Fase 1) de los naviformes de CBII entre 1580 y 1531 cal ANE. Este intervalo surge de tener en cuenta los datos procedentes de la datación MAMS-22644 relativa a los niveles de uso de la Fase 1 del Ámbito 9. Esta no dispone de paralelos arqueológicos fechados por radiocarbono en las islas Pitiusas. No obstante, se sitúa inmediatamente después de los momentos de uso de la estructura megalítica funeraria de Ca na Costa (Costa y Guerrero 2002). De hecho, los dos yacimientos (CBII y Ca na Costa) comparten algunos elementos materiales como los botones de perforación en "V" o algunos tipos cerámicos como los cuencos hemiesféricos. En este sentido, cabe recordar que esta tradición funeraria en Menorca continúa en uso entre el 1550 y 1430 cal ANE (Gili et al. 2006) y que tal vez debería ajustarse más la datación de la estructura funeraria formenterana. Tampoco conocemos datos relativos al momento cuando dicha estructura se amortiza para construir la Fase 2, motivo por el que este intervalo es tan breve y la transición entre ambas ('Límite Transición 1/2') es tan amplia (1586-958 cal ANE). Es posible que este límite inferior no sea muy representativo y pueda acotarse mediante nuevas muestras. De hecho, en base a un buen número de dataciones obtenidas directamente de los niveles de uso de los naviformes con secuencias radiométricas claras como los de Closos de Can Gaià, Hospitalet Vell o Son Baduia, se puede situar el límite inferior de estos primeros niveles de ocupación ca.1100-1000 cal ANE. Entonces muchos de es-

\footnotetext{
7 Véase n. 2
}

tos poblados sufren notables reestructuraciones en el marco de transformaciones sociales más importantes que, de hecho, dan lugar a lo que se conoce como periodo prototalayótico (Lull et al. 2008) o Bronce Final Balear (Guerrero et al. 2007), que de momento está restringido a Mallorca y Menorca.

Además este último intervalo temporal observado en el modelo bayesiano ('Límite Transición $1 / 2$ ') refiere también a las remodelaciones o reestructuraciones al tener en consideración los datos procedentes de las dataciones MAMS-22644 y MAMS-22643, pues sabemos que en el Ámbito 9, estas son posteriores a la Fase 1 y necesariamente anteriores al uso de la Fase 2, aunque resulta un intervalo igualmente muy amplio en este caso. Sí creemos necesario recordar los casos de otros poblados que presentan reestructuraciones importantes, no únicamente en los naviformes, sino en construcciones adyacentes que a menudo tenían actividades complementarias. El de Closos de Can Gaià es posiblemente el mejor estudiado, pues documenta todo un conjunto de estructuras anexas a los naviformes (Área II), construidas $c a$. 1300 cal ANE (Oliver 2005), del mismo modo que otros elementos estructurales como los muros de cierre de la entrada del Naviforme 1 pueden fecharse en $c a .1 .100 / 1000$ cal ANE. Construcciones similares se han podido registrar en otros lugares, como el naviforme Alemany o el naviforme B de Canyamel, y se conocen también en los Ámbitos 7 y 9 de CBII.

Hay que señalar también que la introducción de la función Interval (Bronk Ramsey 2009; Reimer et al. 2013) permite proponer al modelo la posibilidad de calcular un hiato entre fases, en CBII entre la Fase 1 y la Fase 2. Actualmente no lo hemos identificado a nivel estratigráfico, aunque podría existir entre los distintos naviformes del poblado. La distribución actual de las fechas lo hace posible a nivel estadístico entre 0 y 638 años, aunque solo con series más amplias de dataciones podremos esclarecer si existió realmente.

Además hemos sido capaces de acotar el uso de la Fase 2 (997-927 cal ANE). Este intervalo surge de tener en consideración los datos procedentes de la datación MAMS-22643, la única relativa al uso de la Fase 2 del Ámbito 9. Posiblemente corresponde, en concreto, a un uso cercano al abandono de esta estructura. En este

Trab. Prehist., 74, N. ${ }^{\circ}$ 2, julio-diciembre 2017, pp. 319-334, ISSN: 0082-5638

doi: $10.3989 /$ tp.2017.12197 
sentido, esta datación pone de manifiesto que CBII estuvo ocupado de manera contemporánea a otros yacimientos pitiusos como Sa Murada de Sa Cala (Ramón y Colomar 1999, 2010) y la necrópolis de Can Sergent (Costa y Fernández 1992), yacimientos también fechados por radiocarbono y con los que se solapa perfectamente (véase Tab. 1). Por otra parte, son numerosos los poblados naviformes que permanecen aún en uso, por ejemplo los de Closos de Can Gaià (CNA58, KIA-11232), Hospitalet (KIA-41549, KIA41550) o Son Baduia (UTC-4859), que presentan dataciones comprendidas entre $c a .1000$ y $800 \mathrm{cal}$ ANE (Micó 2005; Ramis y Salas 2014). Incluso todavía se construyen estructuras de nueva planta, pero estas ya empiezan a desmarcarse del modelo naviforme clásico, tal y como queda constatado en Es Figueral de Son Real (Rosselló-Bordoy y Camps 1972).

Por último el abandono del poblado de CBII no fue un evento que produjera un nivel estratigráfico reconocible pues, como venimos explicando, parece que ocurrió de una manera organizada y planificada. Debió suceder en algún momento posterior a 997 o bien entre 994 y 728 cal ANE ('Límite Fin 2'), fecha que surge de tener en consideración los datos procedentes de la datación MAMS-22643, correspondiente al uso de la Fase 2 del Ámbito 9. Este siguió en funcionamiento durante un período de tiempo que desconocemos antes de ser definitivamente abandonado. Aunque esta parece una pauta generalizada en muchos naviformes, otras estructuras sí presentan finales más abruptos o acabaron generando estratigrafías complejas, pues se instalaron construcciones talayóticas encima. Los casos más relevantes tal vez sean los del naviforme doble de Son Oms (Pons 1999), donde se construyó una plataforma escalonada en época talayótica, o bien el naviforme Alemany (Enseñat 1971; Albero et al. 2013; Calderón et al. 2014), que tenía un importante nivel de incendio. El abandono en CBII se produciría de manera contemporánea al de yacimientos prehistóricos de Formentera como la Murada de Sa Cala y también de Ibiza como la necrópolis de Can Sergent. Este hecho coincide con las primeras fechas disponibles para contextos fenicios en Ibiza. Dejando de lado las referencias de los textos clásicos, que sitúan la fundación sobre el 654 ANE (Diodoro Sículo, V, 16, 2-3; citado por
Fernández y Costa 1992), varias evidencias permiten retrasar hasta el siglo VIII ANE los datos procedentes del poblado de Sa Caleta (Ramón 2007) y hasta el 896-824 cal ANE (UtC-11186) varias cremaciones arcaicas procedentes de la necrópolis de Puig des Molins (Fernández y Costa 2004) (véase Tab. 1). Este hecho permite plantear ya una más que probable relación entre ambos acontecimientos históricos.

\section{CONCLUSIONES}

A lo largo de este trabajo se recogen un conjunto de datos que creemos fundamentales para la comprensión de los procesos históricos que configuran las sociedades prehistóricas de las Pitiusas, modificando notablemente la percepción que se tenía de ellas.

Gracias a la secuencia cronológica que podemos inferir con los datos disponibles para CBII se puede constatar la ocupación del lugar entre ca. 1650 y 900 cal ANE con 2 fases constructivas diferenciadas. Dicha secuencia encaja a grandes rasgos con los planteamientos básicos de la periodización actualmente aceptada para las sociedades naviformes y prototalayóticas en las Islas Baleares. No obstante, en Formentera puede plantearse que el inicio de este grupo arqueológico sea algo anterior a lo que actualmente se plantea para el resto de las islas del archipiélago. Del mismo modo, se dota del anclaje cronológico necesario al conjunto de datos socioeconómicos procedentes de las recientes investigaciones llevadas a cabo en Cap de Barbaria II. Los datos disponibles permiten conocer las primeras fases de poblamiento humano en la isla, y posibilitan plantear interesantes procesos de gestión y explotación de los recursos locales, adaptaciones al medio insular u otras dinámicas de interacción con el medio ambiente y eventuales contactos con las comunidades prehistóricas coetáneas del Mediterráneo occidental.

Finalmente, con los datos disponibles es plausible situar el final de las sociedades que habitaban CBII y otros yacimientos prehistóricos pitiusos, como causa o efecto de la fundación de las colonias fenicias de Ibiza, ubicadas en Sa Caleta y el Puig de Vila. Pese a todo, resulta deseable que nuevas dataciones y nuevos contextos ven- 
gan a confirmar y acotar estas afirmaciones, para comprender mejor cada una de las fases descritas y aproximarnos a cómo se relacionan las diferentes dinámicas históricas en las distintas islas del archipiélago balear.

\section{BIBLIOGRAFÍA}

Albero, D. J.; Calderón, M.; García, E.; Gloaguen, E. y Calvo, M. 2013: "El naviforme Alemany 40 años después: puesta en valor y propuestas interpretativas". Boletín de la Sociedad Arqueológica Luliana 69: $15-41$.

Alcover, J. A. 2008: "The First Mallorcans: Prehistoric Colonization in the Western Mediterranean". Journal of World Prehistory 21: 19-84. doi:10.1007/ s10963-008-9010-2

Anglada, M.; Ferrer, T.; Ramis, D.y Salas, M. 2013: "Resultats preliminars del projecte Entre Illes: el cas dels jaciments de Sa Ferradura (Manacor) i Cala Morell (Ciutadella)". En M. Riera y J. Cardell (eds.): $V$ Jornades d'arqueologia de Les Illes Balears. (Palma 2012): 51-58. Palma de Mallorca.

Bayliss, A.; Ramsey, C. B.; van der Plicht, J. y Whittle, A. 2007: "Bradshaw and Bayes: towards a timetable for the Neolithic". Cambridge Archaeological Journal 17 (1): 1-28.

Bevington, P. R. 1969: Data reduction and error analysis for the physical sciences. McGraw Hill. Nueva York.

Bronk Ramsey, C. 2009: "Bayesian analysis of radiocarbon dates". Radiocarbon 51: 337-360.

Buck, C. E., Litton, C. D., Smith, A. F. M. 1992: “Calibration of radiocarbon results pertaining to related Aarchaeological eEvents". Journal of Archaeological Science 19(5): 497-512.

Calderón, M.; Gloaguen, E.; Albero, D.; Garcia, E. y Calvo, M. 2014: "Análisis estratigráfico de la intervención arqueológica en la naveta Alemany 20102011". En M. Riera y J. Cardell (eds.): V Jornades d'Arqueologia de les Illes Balears (Palma 2012): 79-88. Palma de Mallorca.

Castro, P. y Micó, R. 1995: “El C14 y la resolución de problemas arqueológicos. La conveniencia de una reflexión". Revista d'Arqueologia Ponent 5: 252-260.

Costa, B. y Benito, N. 2000: "El poblament de les illes Pitiüses durant la prehistòria. Estat actual de la investigació". En V. M. Guerrero y S. Gornés (eds.): Colonización humana en medios insulares. Interacción con el medio y adaptación cultural. Universidad de las Islas Baleares. Palma de Mallorca: 215-315.
Costa, B. y Fernández, J. H. 1992: "Les Illes Pitiüses: de la prehistòria a la fi de l'època púnica". En G. Rosselló-Bordoy (ed.): X Jornades d'estudis histories locals (Palma 1991). La Prehistòria de Les Illes de La Mediterrània Occidental: 277-355. Palma de Mallorca.

Costa, B. y Guerrero, V. M. 2002: "Balance y nuevas perspectivas en la investigación prehistòrica de las Islas Pitiusas". En W. Waldren y J. Ensenyat (eds.): World Islands in Prehistory. International Insular Investigations. V Deia International Conference of Prehistory. British Archaeological Reports International Series 1095, BAR Publishing. Oxford: 484-501.

Dawson, H. 2010: "A question of life or death? Seafaring and abandonment in the Mediterranean and Pacific Islands". En A. Anderson, J. H. Barrett y K. V. Boyle (eds.): The Global Origins and Development of Seafaring. McDonald Institute Monographs. Cambridge, UK: 203-212.

Enseñat Enseñat, C. 1971: "Excavaciones en el naviforme 'Alemany' Magaluf (Calvià, Mallorca)". Noticiario Arqueológico Hispanico: 39-73.

Fernández, J. H. y Costa Ribas, B. 2004: "Mundo funerario y sociedad en la Eivissa arcaica. Una aproximación al análisis de los enterramientos de cremación de la necrópolis des Puig des Molins". En A. González Prats (ed.): El mundo funerario: Actas del III Seminario Internacional sobre temas fenicios (Guardamar del Segura 2002): Homenaje Al Prof. D. Manuel Pellicer Catalán: 315-408. Alicante.

Fernández, J. H. y Topp, C. 1984: “The Prehistory of Eivissa and Formentera". En H. Kuhbier, J. A. Alcover y M. L. Guerau d'Arellano Tur (eds.): Biogeography and Ecology of the Pityusic Islands. Dr W. Junk Publishers. The Hague, Boston, Lancaster: 565-595.

Gili, S.; Micó, R.; Rihuete, C. y Risch, R. 2006: "An island decides: megalithic burial rites in Minorca". Antiquity 80: 829-842.

Gómez Bellard, C. 2003: "Colonos sin indígenas: el campo ibicenco en época fenicio-púnica”. En C. Gómez Bellard. (ed.): Ecohistoria del paisaje agrario. La agricultura fenicio-púnica en el Mediterráneo. Universitat de València. Valencia.

Gómez Bellard, C. y San Nicolas, M. P. 1988: "La prehistoria de Ibiza y Formentera: estado actual de la investigación". Trabajos de Prehistoria 45: 201-228.

Guerrero, V. M.; Calvo, M.; García, J. y Gornés, S. 2007. Prehistoria de las Islas Baleares. Registro arqueológico y evolución social antes de la Edad del Hierro. British Archaeological Reports International Series 1690, Archaeopress. Oxford.

Juan, G. y Plantalamor, L. 1997: Memòria de les excavacions a la naveta de Cala Blanca. 1986-1993. Treballs del Museu de Menorca 21. Maó. 
López-Dóriga, I. 2014: “¿Por qué datar carporrestos arqueológicos por radiocarbono?”. Nailos 1: 167-180.

López-Dóriga, I.; Picornell, L.; Sureda, P.; Camarós, E.; Cueto, M. y Teira, L. 2015: “Aproximación a la explotación de los recursos vegetales en Cap de Barbaría II: resultados preliminares". En G. Graziani (ed.): Actes de VI Jornades d'Arqueologia de les Illes Balears (Formentera 2014): 143-150. Formentera.

López Garí, J. M.; Pérez Jordà, G.; Marlasca Martín, R.; Farrera Fernández, V. y Enrich Hoja, J. 2013: "La primera agricultura Pitiusa y Balear: las evidencias de la Cova des Riuets". Sagvntvm. Papeles del Laboratorio de Arqueología de Valencia 45: 65-77.

Lull, V.; Micó, R.; Palomar, B.; Rihuete, C. y Risch, R. 2008: Cerámica talayótica. La producción alfarera mallorquina entre ca. 900 y 550 antes de nuestra era. Ed. Bellaterra. Barcelona.

Lull, V.; Micó, R.; Rihuete, C. y Risch, R. 1999: Cova des Càrritx y la Cova des Mussol: ideología y sociedad en la prehistoria de Menorca. Consell Insular de Menorca. Menorca.

Lull, V.; Micó, R.; Rihuete, C. y Risch, R. 2015: "When 14C dates fall beyond the limits of uncertainty: an assessment of anomalies in Western Mediterranean Bronze Age 14C series". Radiocarbon 57: 10291040.

Mangerud, J. 1972: "Radiocarbon dating of marine shells, including a discussion of apparent age of recent shells from Norway". Boreas 1: 143-172.

Micó, R. 2005: Cronología absoluta y periodización de la Prehistoria de las Islas Baleares. British Archaeological Reports International Series 1373, Archaeopress. Oxford.

Oliver, L1. 2005: "Les datacions radiocarbòniques als Closos de Can Gaià (Mallorca)". Mayurqa 30: 245-262.

Plantalamor, L. 1991: L'arquitectura prehistòrica $i$ protohistòrica de Menorca i el seu marc cultural. Treballs del Museu de Menorca 12. Maó.

Plantalamor, L. y Anglada, J. 1978: "Excavacions a les navetes d'habitació de Clariana- Ciutadella (Menorca)". Fonaments 1: 205-208.

Pons, B. 1999: Anàlisis espacial del poblament del Pretalaiòtic Final i Talaiòtic I de Mallorca. Colección La Deixa 2, Consell Insular de Mallorca. Palma.

Ramis, D. 2014: "Early Island Exploitations: Productive and Subsistence Strategies on the Prehistoric Balearic Islands". En A. B. Knapp y P. Van Dommelen (eds.): The Cambridge Prehistory of the Bronze and Iron Age Mediterranean. Cambridge University Press, New York: 40-56.

Ramis, D.; Plantalamor, L.; Carreras, J.; Trias, M. y Santandreu, G. 2007: "S'Arenalet de Son Colom (Arta) i l'origen de l' arquitectura ciclòpia a les Balears". Bolleti de la Societat Arqueològica Lul-liana 63: 333-348.
Ramis, D. y Salas, M. 2014: "Chronology of the S'Hospitalet Vell naveta village: an example of Bronze Age Settlement in the Balearic Islands". Radiocarbon 56: 375-385. doi:10.2458/56.17019

Ramón, J. 2007. Excavaciones arqueológicas en el asentamiento fenicio de sa Caleta (Ibiza). Cuadernos de arqueología mediterránea 16, Bellaterra. Barcelona.

Ramón, J. y Colomar, M. 1999: "Investigacions arqueològiques a la fortificació prehistòrica de sa Cala (La Mola, Formentera)". Mayurqa 25: 29-41.

Ramón, J. y Colomar, M. 2010: "El recinte fortificat de l'Edat del Bronze y l'hàbitat andalusí de Sa Cala (Formentera)". Quaderns de Prehistòria i Arqueologia 28: 139-166.

Reimer, P. J.; Bard, E.; Bayliss, A.; Beck, J. W.; Blackwell, P. G.; Bronk Ramsey, C.; Buck, C. E.; Cheng, H.; Edwards, R. L.; Friedrich, M.; Grootes, P. M.; Guilderson, T. P. y Haflidason, H. J. 2013: "IntCal13 and Marine13 Radiocarbon Age Calibration Curves 0-50,000 Years cal BP'. Radiocarbon 55: 1869-1887. doi:10.2458/azu js_rc.55.16947

Reimer, P. J. y McCormac, F. G. 2002: "Marine radiocarbon reservoir corrections for the Mediterranean and Aegean Seas". Radiocarbon 44:159-166.

Rosselló Bordoy, G. 1983. El Poblado prehistórico de Hospitalet Vell, Manacor. Institut d'Estudis Baleàrics. Palma de Mallorca.

Rosselló Bordoy, G. y Camps, J. 1972: "Excavaciones en el complejo Noroeste de "Es Figueral de Son Real" (Sta. Margarita, Mallorca)". Noticiario Arqueológico Hispánico. Prehistoria: 111-176.

Salvà, B. y Hernández-Gasch, J. 2009: “Los espacios domésticos en las Islas Baleares durante las Edades del Bronce y del Hierro. De la sociedad naviforme a la talayótica". En C. Belarte (ed.): L'espai domèstic $i$ l'organització de la societat a la protohistòria de la Mediterrània occidental (1er millenni aC). Actes de la IV Reunió Internacional d'Arqueologia de Calafell (Calafell, Tarragona 2007): 299-322. Barcelona.

Siani, G.; Paterne, M.; Arnold, M.; Bard, E.; Métivier, B.; Tisnerat, N. y Bassinot, F. 2000: "Radiocarbon reservoir ages in the Mediterranean Sea and Black Sea". Radiocarbon 42: 271-280.

Sureda, P.; Camarós, E., Cantoni, G., Garcia, D., Gonzalo, X., Marín, D., Masclans, A., Molina, A., Bofill, M., Cueto, M. y Álvarez-Fernández, E. 2013: "Redescobrint Cap de Barbaria II. Resultats de la $6^{\mathrm{a}}$ campanya d'excavacions arqueològiques". En M. Riera y J. Cardell (eds.): V Jornades d'Arqueologia de Les Illes Balears (Palma 2012): 15-24. Palma de Mallorca.

Sureda, P.; Camarós, E.; Cueto, M.; Teira, L. C.; Aceituno, F. J.; Albero, D.; Álvarez-Fernández, E.; Bofill, M.; López-Dóriga, I.; Marín, D.; Masclans, A.; Picornell, Ll.; Revelles, J. y Burjachs, F. 2017: "Surviving on the isle of Formentera (Balearic Is- 
lands): adaptation of economic behaviour by Bronze Age first settlers to an extreme insular environement". Journal of Archaeological Science: Reports 12: 860-875.

Topp, C.; Fernández, J. H. y Plantalamor, L. 1979: "Recent archaeological activities in Ibiza and For- mentera". Bulletin of the Institute of Archaeology: 215-231.

Van Strydonck, M.; Boudin, M. y Ramis, D. 2010: "Primer intent de mesurar l'edat del compartiment marí de $14 \mathrm{C}$ de les aigües costaneres de les Illes Balears". Endins 34: 181-188. 